\title{
Does the Society of Thoracic Surgeons risk score accurately predict operative mortality for patients with pulmonary hypertension?
}

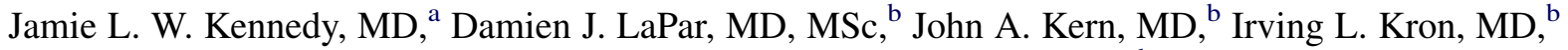 \\ James D. Bergin, MD, ${ }^{\mathrm{a}}$ Sandeep Kamath, MD, ${ }^{\mathrm{a}}$ and Gorav Ailawadi, MD ${ }^{\mathrm{b}}$
}

Objective: This study assessed the impact of pulmonary hypertension (PH) on morbidity and mortality after the most common cardiac operations and evaluated the accuracy of the Society of Thoracic Surgeons (STS) risk model for patients with PH.

\begin{abstract}
Methods: At a single center between 1994 and 2010, all adult cardiac operations performed with recorded preoperative mean pulmonary arterial pressure (MPAP) and STS predicted mortality were reviewed. MPAP was defined as normal $(<25 \mathrm{~mm} \mathrm{Hg})$ or as mild $(25-34 \mathrm{~mm} \mathrm{Hg})$, moderate $(35-44 \mathrm{~mm} \mathrm{Hg})$, or severe $(\geq 45 \mathrm{~mm} \mathrm{Hg}$ ) PH. Multivariate analysis was performed to elucidate the contribution of $\mathrm{PH}$ to morbidity and mortality.
\end{abstract}

Results: In all, 3343 patient records were reviewed. Coronary artery bypass grafting (CABG) was the most common procedure $(67.5 \%)$, followed by aortic valve replacement $(24.9 \%)$ and mitral valve procedures $(6.3 \%)$. Postoperative complications and mortality increased with increasing MPAP. Multivariable analysis found that both moderate (odds ratio, 7.17; $P<.001$ ) and severe (odds ratio, 13.73; $P<.001$ ) PH were significantly associated with increased mortality, even after accounting for STS risk. A subset analysis of isolated CABG cases revealed markedly increased mortality for all categories of $\mathrm{PH}$ (mild odds ratio, 1.99; moderate odds ratio, 11.5; severe odds ratio, 38.9; $P<.001)$.

Conclusions: Morbidity and mortality were independently associated with PH. Observed mortality was significantly higher than predicted by the STS model for patients with moderate and severe $\mathrm{PH}$, particularly in isolated CABG. Addition of PH to the STS risk model should be considered, or alternative tools should be used to assess risk in these patients. (J Thorac Cardiovasc Surg 2013;146:631-7)

Earn CME credits at

http://cme.ctsnetjournals.org

Pulmonary hypertension $(\mathrm{PH})$ is defined as the presence of elevated pulmonary arterial pressure, specifically mean pulmonary arterial pressure (MPAP) greater than $25 \mathrm{~mm} \mathrm{Hg} .{ }^{1}$ In patients with acquired cardiac disease, $\mathrm{PH}$ is most often due to elevated left atrial pressure. ${ }^{2}$ Long-standing high left atrial pressure can lead to pulmonary vascular remodeling, as evidenced by elevated pulmonary vascular resistance (PVR) or transpulmonary gradient. ${ }^{2}$ The most effective therapy for PH related to left-sided heart disease is correction of the underlying cardiac pathology, such as aortic

\footnotetext{
From the Divisions of Cardiology ${ }^{\mathrm{a}}$ and Thoracic and Cardiovascular Surgery, ${ }^{\mathrm{b}}$ University of Virginia Health System, Charlottesville, Va.

Disclosures: Authors have nothing to disclose with regard to commercial support.

Received for publication May 2, 2012; revisions received June 24, 2012; accepted for publication July 26, 2012; available ahead of print Sept 17, 2012.

Address for reprints: Gorav Ailawadi, MD, Division of Thoracic and Cardiovascular Surgery, University of Virginia Health System, PO Box 800679, Charlottesville,

VA 22908 (E-mail: gorav@ virginia.edu).

$0022-5223 / \$ 36.00$

Copyright (C) 2013 by The American Association for Thoracic Surgery

http://dx.doi.org/10.1016/j.jtcvs.2012.07.055
}

valve replacement (AVR) for aortic stenosis; however, $\mathrm{PH}$ has long been recognized as a risk factor for morbidity and mortality for patients undergoing cardiac surgery. A host of perioperative factors, such as protamine, hypoxia, hypercapnia, positive pressure ventilation, and systemic inflammatory response to cardiopulmonary bypass and blood products can exacerbate underlying $\mathrm{PH}$ and result in right ventricular failure, with additional morbidity and mortality. $^{3}$

The Society of Thoracic Surgeons (STS) risk model evolved to guide surgeons and cardiologists by estimating risk of operative mortality on the basis of multiple risk factors, including patient demographic characteristics, comorbidities, procedure, and clinical status. Importantly, pulmonary arterial pressure is not one of these preoperative variables, because it is infrequently measured and is dependent on the "clinical state and volume-loading status of the patient when the measurement is obtained." comparison, the EuroSCORE risk model does include $\mathrm{PH}$, defined as pulmonary arterial systolic pressure (PASP) greater than $60 \mathrm{~mm} \mathrm{Hg} .^{5}$ Moreover, the recently released EuroSCORE II model further stratifies $\mathrm{PH}$ into moderate (PASP $31-55 \mathrm{~mm} \mathrm{Hg}$ ) and severe (PASP $>55 \mathrm{~mm} \mathrm{Hg})^{6}$ Although the use of PASP is attractive because it can be estimated noninvasively by echocardiography, there can be significant differences between 


$$
\begin{aligned}
& \text { Abbreviations and Acronyms } \\
& \text { AVR }=\text { aortic valve replacement } \\
& \text { CABG }=\text { coronary artery bypass grafting } \\
& \text { CI }=\text { confidence interval } \\
& \text { MPAP }=\text { mean pulmonary arterial pressure } \\
& \text { OR }=\text { odds ratio } \\
& \text { PASP }=\text { pulmonary arterial systolic pressure } \\
& \text { PH }=\text { pulmonary hypertension } \\
& \text { PROM }=\text { predicted risk of mortality } \\
& \text { PVR }=\text { pulmonary vascular resistance } \\
& \text { STS }=\text { Society of Thoracic Surgeons }
\end{aligned}
$$

noninvasive estimates and the criterion standard of invasive measurement. ${ }^{7}$

This study sought to assess the impact of $\mathrm{PH}$ in cardiac surgery. We hypothesized that $\mathrm{PH}$ is associated with greater morbidity and mortality for patients undergoing cardiac operations and that the STS risk model is not valid for patients with significant $\mathrm{PH}$. We included a subset analysis of patients undergoing isolated coronary artery bypass grafting $(\mathrm{CABG})$, because the literature on $\mathrm{PH}$ in this most common cardiac operation is limited. We hypothesized that $\mathrm{PH}$ would be an independent risk factor for mortality for patients undergoing $\mathrm{CABG}$ as well.

\section{MATERIALS AND METHODS \\ Patients}

The University of Virginia institutional review board approved this study, including a waiver for individual patient consent.

A total of 11,983 adult cardiac operations were performed at the University of Virginia during the study period of January 1, 1994, to December 3, 2010, and were evaluated for inclusion in this study. Patient records from our institutional STS Adult Cardiac Surgery Database were queried. A total of 5241 case records reported MPAP, and 5241 cases had a calculated STS predicted risk of mortality (PROM). A total of 3343 cases included both MPAP and PROM, and these comprise the study population. All included procedures represent standard surgical approaches, and standard STS variable definitions were used. Patient preoperative risk was assessed by the calculated STS PROM for each patient at the time of the operation. MPAP was the first recorded value after placement of the pulmonary artery catheter before incision.

\section{Outcomes}

The primary outcomes of interest included differences between observed and expected mortalities for patients with varying severity of $\mathrm{PH}$, as well as risk-adjusted associations between mortality and morbidity and degree of PH. Secondary outcomes included observed differences in patient morbidity, mortality, and resource use. Operative mortality was defined as all patient deaths occurring during hospitalization as well those within 30 days of the date of surgery regardless of discharge status. A composite outcome of major complications was used as a proxy for major morbidity and included the cumulative incidence of postoperative stroke, perioperative myocardial infarction, renal failure, prolonged mechanical ventilation, and pneumonia. Standard STS definitions for postoperative events and complications were used, including prolonged mechanical ventilation ( $>24$ hours), new-onset atrial fibrillation, and renal failure (increase in serum creatinine level $>2.0$ or double the most recent preoperative creatinine level).

\section{Statistical Analysis}

All study outcomes and data comparisons were established a priori before data collection. Descriptive, univariate statistics included either Pearson $\chi^{2}$ test or Fisher's exact test for categoric variables and either independent sample single-factor analysis of variance for parametric data comparisons or the Mann-Whitney $U$ test for nonparametric data comparisons. Continuous variables are expressed as either mean $\pm \mathrm{SD}$ or median with interquartile range, depending on overall variable distribution.

Multiple logistic regression analysis was used to estimate confounderadjusted associations between PH category and patient morbidity (major complications) and operative mortality. Models were adjusted for patient risk by inclusion of the STS PROM score as well as operating surgeon and operative year. Confounder-adjusted measures of association are reported as odds ratios (ORs) with $95 \%$ confidence interval (CI). Model performance and the ability of the model to discriminate between dependent outcomes (major complications and mortality) were assessed with the area under the receiver operating characteristic curve. Predictive Analytics SoftWare (PASW version 18.0.0; IBM Corporation, Armonk, NY) was used for all data manipulation and statistical analyses.

\section{RESULTS}

\section{Baseline and Operative Characteristics Stratified by MPAP}

Although ages were similar across groups, the proportion of female patients increased with increasing MPAP (Table 1). Risk factors, including renal failure, lung disease, cerebrovascular disease, and New York Heart Association class IV heart failure, were all more common with increasing severity of $\mathrm{PH}(P<.001$ for all). Left ventricular ejection fraction decreased with increasing MPAP $(P<.001)$. Interestingly, the incidence of acute myocardial infarction did not vary with MPAP, and the incidences of angina, left main disease, and multivessel disease decreased with increasing MPAP.

Operative characteristics also varied considerably with increasing MPAP. Patients with normal or mildly elevated MPAP were more likely to undergo CABG, whereas patients with moderate or severe PH were more likely to undergo valve operations. Reoperations were more common with increasing MPAP. Accounting for these variations in risk factors and operations, the STS PROM increased with increasing MPAP (normal, 1.8\%; mild, 2.3\%; moderate, $4.6 \%$; severe, $5.2 \% ; P<.001$ ). Finally, crossclamp and CPB times were significantly longer in patients with increasing MPAP.

\section{Adjusted and Unadjusted Risks Rise With Increasing MPAP}

Complications occurred more frequently with increasing MPAP (Table 2). Pneumonia, prolonged mechanical ventilation, and renal failure were all significantly associated with $\mathrm{PH}$, as were rare but catastrophic complications such as cardiac arrest. The composite incidence of major complications increased significantly with higher MPAP (normal, 
TABLE 1. Patient risk factors and operative characteristics stratified by mean pulmonary arterial pressure

\begin{tabular}{|c|c|c|c|c|c|c|}
\hline & \multirow[b]{2}{*}{ Total } & \multicolumn{4}{|c|}{ MPAP $(\mathbf{m m ~ H g})$} & \multirow[b]{2}{*}{$P$ value } \\
\hline & & Normal, $<25$ & Mild, 25-34 & Moderate, 35-44 & Severe, $>44$ & \\
\hline $\mathrm{N}$ & 3343 & 1816 & 1068 & 334 & 125 & \\
\hline Age $(y$, mean \pm SD $)$ & $65.6 \pm 11.5$ & $65.9 \pm 11.3$ & $65.7 \pm 11.7$ & $66.2 \pm 11.3$ & $64.2 \pm 11.4$ & .306 \\
\hline Female (no.) & $1017(30.4 \%)$ & $508(28 \%)$ & $327(30.6 \%)$ & $131(39.2 \%)$ & $51(40.8 \%)$ & $<.001$ \\
\hline MPAP (median and IQR) & & $20(16-22)$ & $28(26-30)$ & $39(36-41)$ & $50(47-56)$ & $<.001$ \\
\hline \multicolumn{7}{|l|}{ Preoperative comorbidities (no.) } \\
\hline Renal failure & $306(9.2 \%)$ & $133(7.3 \%)$ & $100(9.4 \%)$ & $49(14.7 \%)$ & $24(19.2 \%)$ & $<.001$ \\
\hline Chronic lung disease & $321(9.6 \%)$ & $127(7.0 \%)$ & $127(11.9 \%)$ & $43(12.9 \%)$ & $24(19.2 \%)$ & $<.001$ \\
\hline Peripheral arterial disease & $511(15.3 \%)$ & $237(13.1 \%)$ & $186(17.1 \%)$ & $73(21.9 \%)$ & $18(14.4 \%)$ & $<.001$ \\
\hline Cerebrovascular disease & $556(16.6 \%)$ & $268(14.8 \%)$ & $203(19.0 \%)$ & $55(16.5 \%)$ & $30(24.0 \%)$ & .003 \\
\hline Diabetes mellitus & $1185(35.4 \%)$ & $572(31.5 \%)$ & $426(39.9 \%)$ & $135(40.4 \%)$ & $52(41.6 \%)$ & $<.001$ \\
\hline Dyslipidemia & $2258(67.5 \%)$ & $1249(68.8 \%)$ & $726(68.0 \%)$ & $202(60.5 \%)$ & $81(67.5 \%)$ & .025 \\
\hline Family history of CAD & $1727(51.7 \%)$ & $953(52.5 \%)$ & $562(52.6 \%)$ & $149(44.6 \%)$ & $63(50.4 \%)$ & .055 \\
\hline Hypertension & $2609(78.0 \%)$ & $1403(77.3 \%)$ & $854(80.0 \%)$ & $255(76.3 \%)$ & $97(77.6 \%)$ & .318 \\
\hline \multicolumn{7}{|l|}{ Cardiac disease (no.) } \\
\hline Acute MI & $1068(32.5 \%)$ & $577(31.8 \%)$ & $363(34.0 \%)$ & $107(32.0 \%)$ & $39(31.2 \%)$ & .649 \\
\hline Angina & $1647(49.3 \%)$ & $976(53.7 \%)$ & $505(47.3 \%)$ & $123(36.8 \%)$ & $43(34.4 \%)$ & $<.001$ \\
\hline NYHA class & & & & & & $<.001$ \\
\hline I & $359(10.7 \%)$ & $197(10.8 \%)$ & $115(10.8 \%)$ & $36(10.8 \%)$ & $11(8.8 \%)$ & \\
\hline II & $508(15.2 \%)$ & $321(17.7 \%)$ & $147(13.8 \%)$ & $32(9.6 \%)$ & $8(6.4 \%)$ & \\
\hline III & $740(22.1 \%)$ & $372(20.5 \%)$ & $258(24.2 \%)$ & $77(23.1 \%)$ & $33(26.4 \%)$ & \\
\hline IV & $817(24.4 \%)$ & $355(19.5 \%)$ & $274(25.7 \%)$ & $129(38.6 \%)$ & $59(47.2 \%)$ & \\
\hline Atrial fibrillation (no.) & $301(9.0 \%)$ & $112(6.2 \%)$ & $108(10.1 \%)$ & $58(17.4 \%)$ & $23(18.4 \%)$ & $<.001$ \\
\hline LVEF ( $\%$, median and IQR) & & $55 \%(45 \%-63 \%)$ & $54 \%(40 \%-60 \%)$ & $45 \%(30 \%-60 \%)$ & $45 \%(30 \%-60 \%)$ & $<.001$ \\
\hline Left main disease (no.) & $924(27.6 \%)$ & $538(29.6 \%)$ & $289(27.1 \%)$ & $78(23.4 \%)$ & $19(15.2 \%)$ & .001 \\
\hline Diseased vessels (no.) & & & & & & $<.001$ \\
\hline None & $488(14.6 \%)$ & $224(12.3 \%)$ & $157(14.7 \%)$ & $70(21.0 \%)$ & $37(29.6 \%)$ & \\
\hline 1 & $278(8.3 \%)$ & $134(7.4 \%)$ & $80(7.5 \%)$ & $49(14.7 \%)$ & $15(12.0 \%)$ & \\
\hline 2 & $576(17.2 \%)$ & $328(18.1 \%)$ & $181(16.9 \%)$ & $47(14.1 \%)$ & $20(16.0 \%)$ & \\
\hline 3 & $1992(59.6 \%)$ & $1129(62.2 \%)$ & $646(60.5 \%)$ & $164(49.1 \%)$ & $53(42.4 \%)$ & \\
\hline Status (no.) & & & & & & $<.001$ \\
\hline Elective & $1765(52.8 \%)$ & $986(54.3 \%)$ & $571(53.5 \%)$ & $149(44.6 \%)$ & $59(47.2 \%)$ & \\
\hline Urgent & $1469(43.9 \%)$ & $785(43.2 \%)$ & $463(43.4 \%)$ & $163(48.8 \%)$ & $58(46.4 \%)$ & \\
\hline Emergency & $102(3.1 \%)$ & $42(2.3 \%)$ & $34(3.2 \%)$ & $19(5.7 \%)$ & $7(5.6 \%)$ & \\
\hline Salvage & $5(0.1 \%)$ & $2(0.1 \%)$ & $0(0 \%)$ & $2(0.6 \%)$ & $1(0.8 \%)$ & \\
\hline Procedure (no.) & & & & & & $<.001$ \\
\hline CABG & $2258(67.5 \%)$ & $1367(75.3 \%)$ & $705(66.0 \%)$ & $149(44.6 \%)$ & $37(29.6 \%)$ & \\
\hline Isolated AVR & $833(24.9 \%)$ & $374(20.5 \%)$ & $278(26.0 \%)$ & $125(37.4 \%)$ & $56(44.8 \%)$ & \\
\hline Isolated MVR & $209(6.3 \%)$ & $60(3.3 \%)$ & $69(6.5 \%)$ & $52(15.6 \%)$ & $28(22.4 \%)$ & \\
\hline CABG plus valve & $43(1.2 \%)$ & $15(0.8 \%)$ & $16(1.5 \%)$ & $8(2.4 \%)$ & $4(3.2 \%)$ & \\
\hline Reoperation (no.) & $195(5.8 \%)$ & $76(4.2 \%)$ & $64(6.0 \%)$ & $39(11.7 \%)$ & $16(12.8 \%)$ & $<.001$ \\
\hline Intraoperative blood products (no.) & $856(25.6 \%)$ & $375(20.6 \%)$ & $311(29.1 \%)$ & $128(38.3 \%)$ & $42(33.6 \%)$ & $<.001$ \\
\hline Crossclamp time (min, median and IQR) & & $69(54-91)$ & $73(55-94)$ & $79(62-101)$ & $80(64-108)$ & $<.001$ \\
\hline $\begin{array}{l}\text { Cardiopulmonary bypass time } \\
\text { (min, median and IQR) }\end{array}$ & & $93(75-118)$ & $99(78-125)$ & $109(88-139)$ & $114(88-149)$ & $<.001$ \\
\hline $\begin{array}{l}\text { STS predicted mortality } \\
(\%, \text { median and IQR })\end{array}$ & & $1.8(0.8-4.1)$ & $2.3(1.1-5.3)$ & $4.6(2.3-9.0)$ & $5.2(2.3-11.5)$ & $<.001$ \\
\hline
\end{tabular}

$\overline{A V R}$, Aortic valve replacement; $C A B G$, coronary artery bypass grafting; $C A D$, coronary artery disease; $I Q R$, interquartile range; $L V E F$, left ventricular ejection fraction; $M I$, myocardial infarction; MPAP, mean pulmonary arterial pressure; NYHA, New York Heart Association; STS, Society of Thoracic Surgeons; SD, standard deviation.

$10.4 \%$; mild, $14.3 \%$; moderate, $29.9 \%$; severe, $32.0 \%$; $P<.001)$. As a consequence, hospital stay of patients with at least moderate $\mathrm{PH}$ was on average 2 days longer than that of patients without $\mathrm{PH}$.
As expected, the mortality increased significantly in patients with worsening $\mathrm{PH}$ (normal, $1.2 \%$; mild, $2.1 \%$; moderate, $7.2 \%$; severe, $12.8 \% ; P<.001$ ). Importantly, the observed mortality incrementally increased beyond that 
TABLE 2. Postoperative complications and mortality stratified by median pulmonary arterial pressure

\begin{tabular}{|c|c|c|c|c|c|c|}
\hline & \multirow[b]{2}{*}{ Total } & \multicolumn{4}{|c|}{ MPAP (mm Hg) } & \multirow[b]{2}{*}{$P$ value } \\
\hline & & Normal, $<\mathbf{2 5}$ & Mild, 25-34 & Moderate, 35-44 & Severe, $>44$ & \\
\hline $\mathrm{N}$ & 3343 & 1816 & 1068 & 334 & 125 & \\
\hline Pneumonia & $128(3.8 \%)$ & $42(2.3 \%)$ & $44(4.1 \%)$ & $29(8.7 \%)$ & $13(10.4 \%)$ & $<.001$ \\
\hline Prolonged mechanical ventilation & $331(9.9 \%)$ & $115(6.3 \%)$ & $108(10.1 \%)$ & $77(23.1 \%)$ & $31(24.8 \%)$ & $<.001$ \\
\hline Stroke & $81(2.4 \%)$ & $42(2.3 \%)$ & $22(2.1 \%)$ & $11(3.3 \%)$ & $6(4.8 \%)$ & .191 \\
\hline Renal failure & $178(5.3 \%)$ & $63(3.5 \%)$ & $52(4.9 \%)$ & $45(13.5 \%)$ & $18(14.4 \%)$ & $<.001$ \\
\hline Myocardial infarction & $12(0.4 \%)$ & $7(0.4 \%)$ & $3(0.3 \%)$ & $1(0.3 \%)$ & $1(0.8 \%)$ & .818 \\
\hline Atrial fibrillation & $708(21.2 \%)$ & $356(19.6 \%)$ & $244(22.8 \%)$ & $79(23.7 \%)$ & $29(23.2 \%)$ & .111 \\
\hline Cardiac arrest & $92(2.8 \%)$ & $23(1.3 \%)$ & $32(3.0 \%)$ & $25(7.5 \%)$ & $12(9.6 \%)$ & $<.001$ \\
\hline Reoperation for bleeding or tamponade & $89(2.7 \%)$ & $43(2.4 \%)$ & $22(2.1 \%)$ & $16(4.8 \%)$ & $8(6.4 \%)$ & .002 \\
\hline Multiple organ system failure & $61(1.8 \%)$ & $15(0.8 \%)$ & $12(1.1 \%)$ & $22(6.6 \%)$ & $12(9.6 \%)$ & $<.001$ \\
\hline Major complications & $482(14.4 \%)$ & $189(10.4 \%)$ & $153(14.3 \%)$ & $100(29.9 \%)$ & $40(32.0 \%)$ & $<.001$ \\
\hline Any complication & $1199(35.9 \%)$ & $579(31.9 \%)$ & $395(37.0 \%)$ & $164(49.1 \%)$ & $61(48.8 \%)$ & $<.001$ \\
\hline Hospital stay (postoperative d, median and IQR) & & $5(4-6)$ & $6(5-7)$ & $7(5-11)$ & $7(5-11)$ & $<.001$ \\
\hline Observed mortality & & $21(1.2 \%)$ & $22(2.1 \%)$ & $24(7.2 \%)$ & $16(12.8 \%)$ & $<.001$ \\
\hline
\end{tabular}

Data are number with percentage except as specified. $I Q R$, Interquartile range; $M P A P$, mean pulmonary arterial pressure.

predicted by the STS risk model with increasing severity of $\mathrm{PH}$ (Figure 1). Specifically, in patients with severe PH, the actual mortality was 2.46-fold higher than the STS PROM $(P=.04)$.

To explore this relationship further, a multivariate analysis was performed to evaluate the impact of severity of PH on mortality (Table 3). Relative to patients with normal MPAP, moderate PH was significantly associated with mortality (OR, $7.17 ; P<.001$ ), even after accounting for covariates such as STS PROM. Furthermore, patients with severe $\mathrm{PH}$ had the greatest adjusted risk of mortality (OR, 13.73; $P<.001)$. Multivariate analysis was also performed to assess impact of $\mathrm{PH}$ on major complications (Table 3). Even mild $\mathrm{PH}$ was associated with increased risk of major complications (OR, 1.47), which increased for moderate $(\mathrm{OR}, 3.76)$ and severe PH (OR, 4.24; $P<.001)$.

\section{Risk in Isolated CABG Increases With MPAP}

Because isolated CABG was the most common operation in this cohort, comprising more than 2000 patients, we analyzed the complication rate and mortality in this subset of patients (Table 4). Similar to the evaluation of the entire study cohort, the incidence of postoperative pneumonia, prolonged mechanical ventilation, and renal failure increased with worsening $\mathrm{PH}$. In fact, more than $50 \%$ of patients undergoing CABG with moderate or severe $\mathrm{PH}$ had at least 1 complication, compared with only $30 \%$ for the entire CABG cohort. Mortality increased markedly with increasing MPAP (normal, $0.9 \%$; mild, $1.7 \%$; moderate, $8.1 \%$; severe, $21.6 \% ; P<.001)$ and to a much greater extent than the STS PROM (normal, $1.3 \%$; mild, $1.6 \%$; moderate, $3.8 \%$; severe, $1.7 \%$; $P<.001)$. The ratio of observed to expected mortality is

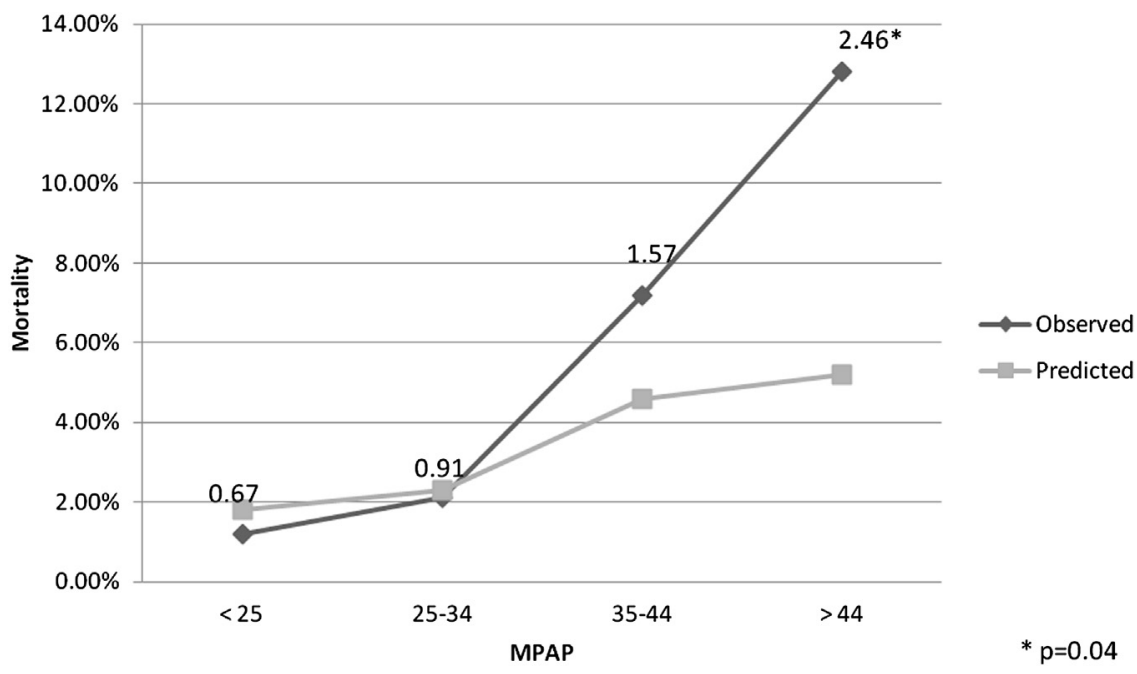

FIGURE 1. Observed and predicted mortalities stratified by mean pulmonary arterial pressure $(M P A P)$ for the entire cohort. 
TABLE 3. Multivariate analysis demonstrating significant association between pulmonary hypertension and mortality and major complications

\begin{tabular}{|c|c|c|c|c|}
\hline & \multicolumn{2}{|c|}{ Mortality } & \multicolumn{2}{|c|}{ Major complications } \\
\hline & OR $(95 \%$ CI $)$ & $P$ value & OR $(95 \%$ CI $)$ & $P$ value \\
\hline \multicolumn{5}{|l|}{ Entire cohort } \\
\hline Normal $(<25)$ & 1 & $<.001$ & 1 & $<.001$ \\
\hline Mild (25-34) & $1.74(0.95-3.18)$ & & $1.47(1.16-1.86)$ & \\
\hline Moderate (35-44) & $7.17(3.91-6.68)$ & & $3.76(2.82-5.02)$ & \\
\hline Severe $(>44)$ & $13.7(6.68-26.8)$ & & $4.24(2.71-6.45)$ & \\
\hline \multicolumn{5}{|l|}{ Isolated CABG } \\
\hline Normal $(<25)$ & 1 & $<.001$ & 1 & $<.001$ \\
\hline Mild (25-34) & $1.99(0.88-4.52)$ & & $1.74(1.29-2.35)$ & \\
\hline Moderate (35-44) & $11.5(4.97-26.7)$ & & $7.19(4.82-10.7)$ & \\
\hline Severe $(>44)$ & $38.9(13.9-109)$ & & $9.02(4.42-18.4)$ & \\
\hline \multicolumn{5}{|c|}{$\begin{array}{l}\text { Pulmonary hypertension categories are given as mean pulmonary arterial pressures } \\
\text { measured in millimeters of mercury. Model discrimination for mortality (areas under } \\
\text { the curve): all patients, } 0.76 \text {; coronary artery bypass grafting only, } 0.80 \text {. Model dis- } \\
\text { crimination for major complications (areas under the curve): all patients, } 0.68 \text {; coro- } \\
\text { nary artery bypass grafting only, } 0.76 \text {. Covariates included mean pulmonary arterial } \\
\text { pressure, Society of Thoracic Surgeons predicted risk of mortality, year of operation, } \\
\text { and surgeon. } C A B G \text {, Coronary artery bypass grafting; } C I \text {, confidence interval; } O R \text {, } \\
\text { odds ratio. }\end{array}$} \\
\hline
\end{tabular}

thus exceedingly high in patients with moderate and especially severe $\mathrm{PH}(P<.001)$.

Multivariate analysis was then performed to evaluate the impact of PH on mortality (Table 3). Even after accounting for STS PROM, patients with moderate PH had an 11.5-fold increased risk of death, whereas patients with severe $\mathrm{PH}$ had 38.9-fold increased risk of death $(P<.001)$. Risk-adjusted analysis of major complications also demonstrated substantially increased risk with increasing severity of $\mathrm{PH}$ (mild OR, 1.74; moderate OR, 7.19; severe OR, 9.02; $P<.001)$.

\section{DISCUSSION}

Accurate assessment of surgical risk is becoming increasingly important as health care reform focuses attention on quality measures. The STS risk model is widely used in the United States to predict operative risk and to compare surgical outcomes across surgeons and hospitals. Equally important, the STS risk model is used to aid medical decision making and to counsel patients on the potential risks of surgical interventions, particularly in light of recent advances in percutaneous therapies. Here we have demonstrated that patients with $\mathrm{PH}$ have greater operative morbidity, including pneumonia, prolonged ventilation, and renal failure. Furthermore, even after accounting for more risk factors, moderate and severe $\mathrm{PH}$ were independently associated with mortality. Although the STS risk model is accurate for patients with normal pulmonary arterial pressures, the model significantly underestimates the actual risk for patients with moderate and severe $\mathrm{PH}$.

\section{PH in Cardiac Surgery}

PH has long been considered a risk factor for morbidity and mortality in cardiac surgery, although the literature on the topic is inconsistent and reveals many unanswered questions. Most studies have been small, single-center retrospective analyses focusing on a single operation. Studies have used various definitions of PH. Invasive and noninvasive measurements of pulmonary pressures have been used almost interchangeably. There is a surprising paucity of recent literature describing the impact of $\mathrm{PH}$ in cardiac surgery, and most studies have focused on valve disease.

Melby and colleagues ${ }^{8}$ recently reported a single-center retrospective analysis of 1080 patients with aortic stenosis undergoing surgical AVR. ${ }^{8} \mathrm{PH}$ (defined as PASP $\geq 35$ ) was independently associated with higher operative mortality. Moreover, long-term mortality was increased in patients with $\mathrm{PH}$, particularly if PVR was elevated at the time of surgery ( $>3$ Wood units) or if PASP remained elevated postoperatively. Ben-Dor and colleagues ${ }^{9}$ published a prospective cohort study of 509 patients with aortic stenosis evaluated at their center for transcatheter AVR as part of the Placement of AoRTic TraNscathetER Valve

TABLE 4. Subgroup analysis of complications and mortality in patients undergoing isolated coronary artery bypass grafting stratified by mean pulmonary arterial pressure

\begin{tabular}{|c|c|c|c|c|c|c|}
\hline & \multirow[b]{2}{*}{ Total } & \multicolumn{4}{|c|}{ MPAP $(\mathbf{m m ~ H g})$} & \multirow[b]{2}{*}{$P$ value } \\
\hline & & Normal, $<\mathbf{2 5}$ & Mild, 25-34 & Moderate, 35-44 & Severe, $>44$ & \\
\hline $\mathrm{N}$ & 2258 & $1367(60.5 \%)$ & $705(31.2 \%)$ & $149(6.6 \%)$ & $37(1.6 \%)$ & \\
\hline Pneumonia & $79(3.5 \%)$ & $32(2.3 \%)$ & $25(3.5 \%)$ & $16(10.7 \%)$ & $6(16.2 \%)$ & $<.001$ \\
\hline Prolonged mechanical ventilation & $191(8.5 \%)$ & $72(5.3 \%)$ & $62(8.8 \%)$ & $46(30.9 \%)$ & $11(29.7 \%)$ & $<.001$ \\
\hline Stroke & $37(1.6 \%)$ & $17(1.2 \%)$ & $13(1.8 \%)$ & $6(4.0 \%)$ & $1(2.7 \%)$ & .071 \\
\hline Renal failure & $114(5.0 \%)$ & $48(3.5 \%)$ & $30(4.3 \%)$ & $27(18.1 \%)$ & $9(24.3 \%)$ & $<.001$ \\
\hline Myocardial infarction & $0(0 \%)$ & $0(0 \%)$ & $0(0 \%)$ & $0(0 \%)$ & $0(0 \%)$ & NA \\
\hline Any complication & $736(32.6 \%)$ & $388(28.4 \%)$ & $248(35.2 \%)$ & $81(54.4 \%)$ & $19(51.4 \%)$ & $<.001$ \\
\hline Major complications & $292(12.9 \%)$ & $120(8.8 \%)$ & $96(13.6 \%)$ & $59(39.6 \%)$ & $17(45.9 \%)$ & $<.001$ \\
\hline Observed mortality & $44(1.9 \%)$ & $12(0.9 \%)$ & $12(1.7 \%)$ & $12(8.1 \%)$ & $8(21.6 \%)$ & $<.001$ \\
\hline Predicted mortality ( $\%$, median and IQR) & & $1.3(0.7 \%-3.3 \%)$ & $1.6(0.9 \%-3.8 \%)$ & $3.8(1.6 \%-7.7 \%)$ & $1.7(1.1 \%-8.2 \%)$ & $<.001$ \\
\hline Observed to expected mortality ratio & & 0.69 & 1.06 & 2.13 & 12.71 & $<.001$ \\
\hline
\end{tabular}

Data are number with percentage except as specified. $I Q R$, Interquartile range; $M P A P$, mean pulmonary arterial pressure; $N A$, not applicable. 
(PARTNER) trial. Pulmonary vascular remodeling was common in patients with severe $\mathrm{PH}$, as demonstrated by elevated PVR ( $>3$ Woods units) in 59\% and elevated transpulmonary gradient $(>12 \mathrm{~mm} \mathrm{Hg})$ in $46 \%$. As expected, overall mortality was higher with increasing PASP, although the authors did not stratify outcomes by intervention (AVR, transcatheter AVR, balloon aortic valvuloplasty, or medical management).

Ghoreishi and colleagues ${ }^{10}$ studied the impact of $\mathrm{PH}$ (defined as PASP $\geq 40$ ) on operative and long-term mortalities following 873 operations for mitral regurgitation. $\mathrm{PH}$ was present in $53 \%$ of patients and was associated with higher operative and long-term mortalities. Complications were also more common in patients with $\mathrm{PH}$, including renal failure requiring dialysis, sepsis, respiratory complications, and longer hospital stay.

Literature on $\mathrm{PH}$ in patients undergoing $\mathrm{CABG}$ is limited. One retrospective study of 2149 patients who underwent $\mathrm{CABG}$ at 2 centers observed higher mortality and postoperative myocardial infarction in patients with $\mathrm{PH}$ before $\mathrm{CPB} .{ }^{11}$ In our study, which included $2258 \mathrm{CABG}$ procedures, we found a stepwise increase in mortality and major complications in patients with increasing severity of $\mathrm{PH}$. We did not observe an increased risk of postoperative myocardial infarction. One of the most striking findings was the observed mortality of $21.6 \%$ for patients undergoing CABG with severe $\mathrm{PH}$, much higher than predicted by STS and much greater than the entire cohort. Although the number of patients with severe $\mathrm{PH}$ undergoing CABG was small, if this finding holds true, then patients undergoing isolated CABG with severe PH may be at the highest risk. A potential explanation for this differential risk between patients undergoing $\mathrm{CABG}$ and those undergoing valvular surgery is the usually rapid reduction in left atrial pressure after correction of valvular pathology, which is less commonly seen after CABG.

\section{Treatment of PH}

During the last 2 decades, there has been a rapid growth in the number and availability of agents to treat $\mathrm{PH}$, both acutely and long term. Pulmonary arterial hypertension resulting from congenital heart disease, connective tissue diseases, or idiopathic causes, has been the primary focus of study. Continuous intravenous epoprostenol, a direct pulmonary vasodilator, has been shown to improve exercise tolerance and survivial. ${ }^{12}$ Bosentan, which acts by blocking the vasoconstriction and smooth muscle proliferation effects of endothelin, also improves exercise tolerance and delays progression of symptoms. ${ }^{13}$ Sildenafil, a phosphodiesterase inhibitor that induces pulmonary vasodilation by increasing cyclic guanosine monophosphate levels, has been shown to increase exercise tolerance. ${ }^{14}$ More recent advances have examined the added value of combination therapy, as well as development of agents with improved side effect profiles and stability, allowing more convenient dosing regimens.

Although the literature supporting the use of these agents in patients with primary pulmonary arterial hypertension is robust, less is known about their use in patients with leftsided heart disease. Sildenafil and bosentan have been used successfully to lower PVR preoperatively for patients with refractory heart failure undergoing cardiac transplantation. ${ }^{15}$ Inhaled nitric oxide and epoprostenol, milrinone, and sildenafil are now commonly used in the perioperative management of cardiac surgical patients, although studies describing their use have been small and focused on hemodynamic rather than clinical end points. ${ }^{8,16-18}$ The frequency of long-term residual $\mathrm{PH}$ after corrective cardiac surgery and the benefit of $\mathrm{PH}$ agents in these patients have not been well characterized.

Our practice in the perioperative management of patients with $\mathrm{PH}$ requiring cardiac surgery has evolved through the years. For elective or urgent cases with evidence of $\mathrm{PH}$ or right ventricular dysfunction, we favor preoperative right heart catheterization to guide optimization of volume status and potential use of pulmonary vasodilators. Intraoperatively, we frequently use milrinone and inhaled epoprostenol, with epinephrine for right ventricular dysfunction if needed. Postoperatively, we are cautious with fluid resuscitation, slowly wean milrinone, and occasionally transition patients to oral sildenafil.

\section{EuroSCORE Versus STS for Cardiac Surgery}

Many models are available to assess operative risk for cardiac surgery, incorporating a variety of patient and operative characteristics. PH is included in the EuroSCORE, Parsonnet, and Tuman models, but not in other commonly employed models, such as STS and Cleveland Clinic calculators. ${ }^{4,5,19-21}$ Nilsson and colleagues ${ }^{22}$ compared 19 models for predicting operative mortality in 6222 cardiac operations. The logistic EuroSCORE model was the most accurate model in their analysis, followed by the additive EuroSCORE model and the Cleveland Clinic model. Unfortunately, the STS model was not included in that study. Direct comparisons of the STS and EuroSCORE models have yielded mixed results. A second study by Nilsson and colleagues ${ }^{23}$ found superior discriminatory power of the additive EuroSCORE model relative to the STS model in a retrospective single-center analysis of isolated CABG operations. ${ }^{23}$ Conversely, several recent studies on AVR for aortic stenosis have found the STS model to be highly accurate in high risk cases, while the EuroSCORE model overestimates operative mortality. ${ }^{24,25}$ Unfortunately, EuroSCORE and EuroSCORE II could not be calculated for our cohort, because PASP and patient mobility information were not available in our database. It is possible that EuroSCORE II would be a more accurate tool for patients with moderate and severe $\mathrm{PH}$. 


\section{Limitations}

There are several limitations to note. This was a singlecenter, retrospective analysis that included relatively few patients with severe $\mathrm{PH}(125 ; 3.8 \%)$. Patients without a measured MPAP were obviously not included, which likely introduced some selection bias. MPAP is a dynamic variable that is dependent on volume status, loading conditions, and ischemia. We stratified patients according to the initial MPAP after the pulmonary artery catheter was placed and before incision. General anesthesia and fasting can falsely lower these values. Elevated MPAP may be due to elevated left atrial pressure, elevated PVR, or a combination of both, and this analysis was not able to differentiate those groups, nor do we have data on reversibility of PVR. The time period for this study was more than 15 years, and substantial changes in the perioperative management of patients with $\mathrm{PH}$ occurred during these years. Finally, because the purpose of this study was to evaluate the validity of the STS risk model in the setting of PH, we only included procedures with a calculated STS risk score, thus comprising a subset of all cases at our institution in the specified time period.

\section{CONCLUSIONS}

$\mathrm{PH}$ is a significant risk factor for morbidity and mortality after common cardiac operations, including $\mathrm{CABG}$, valve operations, and CABG and valve operations together. Although the STS risk model performs well in the setting of normal or mildly elevated pulmonary arterial pressures, it severely underestimates the actual risk in patients with moderate or severe PH. Moreover, moderate and severe $\mathrm{PH}$ are independently associated with mortality even after adjusting for STS risk. Alternative risk models should be considered in patients with $\mathrm{PH}$ to assess risk adequately. In the future, the inclusion of PH to the STS risk model may allow more accurate assessment of actual risk and should be considered.

\section{References}

1. Badesch DB, Champion HC, Sanchez MA, Hoeper MM, Loyd JE, Manes A, et al. Diagnosis and assessment of pulmonary arterial hypertension. J Am Coll Cardiol. 2009;54(1 Suppl):S55-66.

2. McLaughlin VV, Archer SL, Badesch DB, Farber HW, Lindner JR, et al. ACCF/ AHA 2009 expert consensus document on pulmonary hypertension: a report of the American College of Cardiology Foundation Task Force on Expert Consensus Documents and the American Heart Association developed in collaboration with the American College of Chest Physicians; American Thoracic Society, Inc.; and the Pulmonary Hypertension Association. J Am Coll Cardiol. 2009; 53:1573-619.

3. Denault A, Deschamps A, Tardif J, Lambert J, Perrault L. Pulmonary hypertension in cardiac surgery. Curr Cardiol Rev. 2010;6:1-14.

4. Shahian DM, O'Brien SM, Filardo G, Ferraris VA, Haan CK, Rich JB, et al. The Society of Thoracic Surgeons 2008 cardiac surgery risk models: part 1-coronary artery bypass grafting surgery. Ann Thorac Surg. 2009;88(1 Suppl):S2-22.

5. Roques F, Nashef SA, Michel P, Gauducheau E, de Vincentiis C, Baudet E, et al. Risk factors and outcome in European cardiac surgery: analysis of the Euro-
SCORE multinational database of 19,030 patients. Eur J Cardiothorac Surg 1999;15:816-22; discussion, 822-3.

6. European System for Cardiac Operative Risk Evaluation. EuroSCORE Web site. Available at: http://euroscore.org/. Accessed May 30, 2012.

7. Fisher MR, Forfia PR, Chamera E, Housten-Harris T, Champion HC, Girgis RE, et al. Accuracy of Doppler echocardiography in the hemodynamic assessment of pulmonary hypertension. Am J Respir Crit Care Med. 2009;179:615-21.

8. Melby SJ, Moon MR, Lindman BR, Bailey MS, Hill LL, Damiano RJ Jr. Impact of pulmonary hypertension on outcomes after aortic valve replacement for aortic valve stenosis. J Thorac Cardiovasc Surg. 2011;141:1424-30.

9. Ben-Dor I, Goldstein SA, Pichard AD, Satler LF, Maluenda G, Li Y, et al. Clinical profile, prognostic implication, and response to treatment of pulmonary hypertension in patients with severe aortic stenosis. Am J Cardiol. 2011;107: 1046-51.

10. Ghoreishi M, Evans CF, DeFilippi CR, Hobbs G, Young CA, Griffith BP, et al Pulmonary hypertension adversely affects short- and long-term survival after mitral valve operation for mitral regurgitation: implications for timing of surgery. J Thorac Cardiovasc Surg. 2011;142:1439-52.

11. Reich DL, Bodian CA, Krol M, Kuroda M, Osinski T, Thys DM. Intraoperative hemodynamic predictors of mortality, stroke, and myocardial infarction after coronary artery bypass surgery. Anesth Analg. 1999;89:814-22.

12. Barst RJ, Rubin LJ, Long WA, McGoon MD, Rich S, Badesch DB, et al. A comparison of continuous intravenous epoprostenol (prostacyclin) with conventional therapy for primary pulmonary hypertension. The Primary Pulmonary Hypertension Study Group. N Engl J Med. 1996;334:296-301.

13. Rubin LJ, Badesch DB, Barst RJ, Galie N, Black CM, Keogh A, et al. Bosentan therapy for pulmonary arterial hypertension. N Engl J Med. 2002;346:896-903. Erratum in: N Engl J Med. 2002;346:1258.

14. Galiè N, Ghofrani HA, Torbicki A, Barst RJ, Rubin LJ, Badesch D, et al. Sildenafil citrate therapy for pulmonary arterial hypertension. $N$ Engl J Med. 2005; 353:2148-57. Erratum in: N Engl J Med. 2006;354:2400-1.

15. Perez-Villa F, Farrero M, Sionis A, Castel A, Roig E. Therapy with sildenafil or bosentan decreases pulmonary vascular resistance in patients ineligible for heart transplantation because of severe pulmonary hypertension. J Heart Lung Transplant. 2010;29:817-8.

16. Maxey TS, Smith CD, Kern JA, Tribble CG, Jones DR, Kron IL, et al. Beneficial effects of inhaled nitric oxide in adult cardiac surgical patients. Ann Thorac Surg. 2002;73:529-33.

17. Fattouch K, Sbraga F, Sampognaro R, Bianco G, Gucciardo M, Lavalle C, et al Treatment of pulmonary hypertension in patients undergoing cardiac surgery with cardiopulmonary bypass: a randomized, prospective, double-blind study. J Cardiovasc Med (Hagerstown). 2006;7:119-23.

18. Winterhalter M, Simon A, Fischer S, Rahe-Meyer N, Chamtzidou N, Hecker H, et al. Comparison of inhaled iloprost and nitric oxide in patients with pulmonary hypertension during weaning from cardiopulmonary bypass in cardiac surgery: a prospective randomized trial. J Cardiothorac Vasc Anesth. 2008;22: 406-13.

19. Parsonnet V, Dean D, Bernstein AD. A method of uniform stratification of risk for evaluating the results of surgery in acquired adult heart disease. Circulation. 1989;79(6 Pt 2):I3-12. Erratum in: Circulation. 1990;82:1078.

20. Tuman KJ, McCarthy RJ, March RJ, Najafi H, Ivankovich AD. Morbidity and duration of ICU stay after cardiac surgery. A model for preoperative risk assessment. Chest. 1992;102:36-44.

21. Higgins TL, Estafanous FG, Loop FD, Beck GJ, Blum JM, Paranandi L. Stratification of morbidity and mortality outcome by preoperative risk factors in coronary artery bypass patients. A clinical severity score. JAMA. 1992;267:2344-8. Erratum in: JAMA. 1992;268:1860.

22. Nilsson J, Algotsson L, Höglund P, Lührs C, Brandt J. Comparison of 19 preoperative risk stratification models in open-heart surgery. Eur Heart J. 2006; 27:867-74.

23. Nilsson J, Algotsson L, Höglund P, Lührs C, Brandt J. Early mortality in coronary bypass surgery: the EuroSCORE versus The Society of Thoracic Surgeons risk algorithm. Ann Thorac Surg. 2004;77:1235-9; discussion 1239-40.

24. Thourani VH, Ailawadi G, Szeto WY, Dewey TM, Guyton RA, Mack MJ, et al. Outcomes of surgical aortic valve replacement in high-risk patients: a multiinstitutional study. Ann Thorac Surg. 2011;91:49-55; discussion, 55-6.

25. Basraon J, Chandrashekhar YS, John R, Agnihotir A, Kelly R, Ward H, et al. Comparison of risk scores to estimate perioperative mortality in aortic valve replacement surgery. Ann Thorac Surg. 2011;92:535-40. 